\title{
Effect of Implementing Nursing Care Protocol on Critical Patients' Safety Outcomes
}

\author{
Amany Ali Mahmoud', Marwa Mostafa Ragheb², Sabah Said Mohamed ${ }^{3}$ and Rawia Ali \\ Ibrahim $^{4}$ \\ (1) Assistant lecturer at Medical Surgical Nursing, Faculty of Nursing, Benha University, Egypt, (2) \\ Professor of Medical Surgical Nursing, Faculty of Nursing, Benha University, Egypt and (3) Assist \\ Professor of Medical Surgical Nursing, Faculty of Nursing, Benha University, Egypt and (4) \\ Lecturer of Medical Surgical Nursing, Faculty of Nursing, Benha University, Egypt
}

\begin{abstract}
Background: Patients' safety is fundamental to the provision of health care in all settings. However, avoidable adverse events, errors and risks associated with health care remain major challenges for patient safety globally. Aim of study: This study aimed to evaluate the effect of implementing nursing care protocol on critical patients' safety outcomes. Design: A quasi experimental - design was utilized to achieve the aim of this study. Setting: This study was conducted at the general intensive care unit at Benha University Hospital. Subjects: Convenience sample of all available nurses (63 nurses) who are working in Intensive Care Unit (ICU) \& a convenience sample of 60 consecutive eligible patients who attended to ICU within 6 months. Tools of data collection: Data of the present study was collected by using the following three tools. I: Structured Questionnaire for nurses. II: Patient safety practices observational checklist and III: Patients ' safety outcomes checklist. Results: The post mean knowledge and practice scores of nurses regard patients' safety post nursing care protocol implementation were higher than pre implementation, there is a highly significant positive correlation between total nurses' knowledge and their practice at pre and post implementation of nursing care protocol where $p<0$. 001. Conclusion: There was an improvement in patient' safety outcomes for study group than control group after one week with statistically significance difference. Recommendation: In service education should provide in hospital to improve nurses' performance regarding patient safety measures through acquiring knowledge and through implementing the established standards of care which must be updated periodically.
\end{abstract}

Key words: Intensive Care Units, Nurses' Performance, Patient Safety.

\section{Introduction}

Patient safety is fundamental to the provision of health care in all settings. However, avoidable adverse events, errors and risks associated with health care remain major challenges for patient safety globally. Patients contribute significantly to the burden of harm due to unsafe care. Available evidence suggests that hospitalizations in lowand middle-income countries lead to 134 million adverse events annually, contributing to 2.6 million deaths. Estimates indicate that in high-income countries, about 1 in 10 patients is harmed while receiving hospital care (World Health Organization, 2019).

Health care professionals are using multiple methods to improve patient safety and quality outcomes. The most component of patient safety measures are; patient identification, effective communication, prevention of infection, fall prevention, bed sores prevention, high alert medication precaution, administration of medication and blood transfusion, fire and electricity control (Joint Commission International, 2016).

Medication errors in critical care are frequent, serious, and predictable. Critically ill patients are prescribed twice as many medications as patients outside ICU and nearly all will suffer a potentially lifethreatening error at some point during their stay. Medication errors management is a key component of nursing care provision and competence in this role is crucial. The role of 


\section{Amany Ali, Marwa Mostafa, Sabah Said and Rawia Ali}

the nurse in medication management has evolved significantly in recent years and indeed is likely to continue to develop in response to healthcare. This can be achieved by identifying and adopting safety measures and where necessary facilitating a culture that will enhance patient safety (Mohammed \& Abdallah, 2018).

Nosocomial infection is a major public health concern throughout the world, it contributes to elongation of hospital stay, long term or permanent disability and death, each year health systems spend a considerable number of resources, including high end antibiotics, health professional work time and hospital space to treat the consequence of nosocomial infection. Critical ill patients are at high risk of developing infection due to the immune suppression and prolonged hospitalization. Also, the nurses are at high risk of developing blood borne infections due to the unsafe use of injection equipment, other medical devices, and blood products in the critical care units. Several studies recommended that competent infection control practices should be established at critical care units to prevent transmission of bacteria and viruses (Gundlapalli et al., 2018).

Despite all advances in health care, Pressure Ulcers (PUs) remain an old worldwide public health problem related to patient safety. Hospital-acquired PUs are one of the most harmful events in the clinical context. PUs, recently known as pressure injuries, are defined as skin injuries and/or underlying tissue damage localized over a bony prominence, resulting from pressure force and/or pressure combined with shear. PUs result in significant physical, psychological, and social problems related to lower quality of life, increasing dependence, and frailty of patients. They increase health care costs and are recognized as an indicator of the quality of care provided in health care institutions. In most of the clinical contexts, PUs are predictable and preventable with interventions and evidence-based practice guidelines (Gaspar et al., 2019).

Inpatient falls in any setting are generally believed to translate into significant morbidity but falls occurring in a heightened monitored setting such as the ICU are of particular concern. ICUs have unique organizational structures to meet the high intensity workload associated with support of critically ill patients. ICU patients generally have high acuity of illness, multiple organ dysfunction and require at least some enhanced monitoring or advanced life support (invasive and non-invasive ventilation, vasoactive therapy, and renal replacement therapy. Staff nurses may have the greatest impact on reducing patient falls. Due to their 24-hr presence, nurses have the most consistent contact with patients and continually monitor for conditional changes (Najafpour et al., 2019).

Critically ill patients admitted to the intensive care unit commonly suffer from pain that can range from mild to extremely severe. There are many potential causes for pain in critically ill patients during their ICU stay. Pain usually results from the primary disease process and tissue injury, invasive procedures, endotracheal suctioning, immobility, turning and mobilization. As most patients in the intensive care unit are critically ill, they are unable to verbally communicate, and report pain they are experiencing. Therefore, physical signs in these patients must always be monitored to detect and assess pain (Bouldin et al., 2016).

Role of critical care nurses in patient safety is influenced by the specific requirements of the specialty which need continuous, close monitoring of the patient, dynamic data analysis, anticipation of complications, complex decision making, continuous evaluation of interventions, and 
emotional support of the patient and family (Chinn and Kramer, 2017).

\section{Significance of the study:}

Patients' safety is a global health concern, affecting patients in all health care settings, whether in developed or developing countries. Research studies have shown that an estimated average of $10 \%$ of all inpatient admissions result in a degree of unintended patient harm. It is estimated that up to $75 \%$ of these lapses in health care delivery are preventable. In addition to human suffering, unsafe health care exacts a heavy economic toll. Indeed, it is estimated that $5-10 \%$ of expenditure on health is due to unsafe practices that result in patient harm. Most of this is due to system failures rather than the actions of individuals (Elmontsri, Banarsee \& Majeed, 2018).

\section{Aim of the study}

This study aimed to evaluate the effect of implementing nursing care protocol on critical patients' safety outcomes.

\section{Research Hypothesis}

H1- The mean score of nurses' knowledge post the nursing care protocol would be higher than mean score of nurses' knowledge pre protocol implementation.

H2-The mean score of nurses' practice post the nursing care protocol would be higher than mean score of nurses' practice pre protocol implementation.

H3-There would be improving in patients' safety outcomes post the nursing care protocol higher than pre protocol implementation.

\section{Subject and Method}

\section{Research design}

A quasi experimental - design was utilized to achieve the aim of this study.

\section{Setting}

The study was conducted at the general intensive care unit at Benha University Hospital that located at second floor and contain four rooms plus one isolation room each room contain four separated beds equipped with mechanical ventilator.

\section{Sample}

\section{a- Nurses}

Convenience sample of all available nurses (63 nurses) who are working at ICU and are assigned for caring the patients were included in the study. They are willing to participate in the study.

\section{b- Patients}

Convenience sample of 60 consecutive eligible patients who attended to the abovementioned setting within 6 months ago. The subjects were eligible in the study were adult patients from both sexes who are newly admitted not more than 48 hrs with stable condition and free from pressure ulcer. Subjects recruited were allocated and classified into two equal groups, 30 patients (control group) pre protocol who received care according to hospital routine and 30 patients (study group) post protocol who received nursing care protocol.

\section{Tools for data collection}

Data of the present study was collected by using the following three tools.

\section{I: Structured Questionnaire for nurses}

It was designed by the researcher through a review of related and recent literature, it was adapted from (Elgazar, et al, 2020; Burns et al, 2020; Fleming \& Martin 2018; Aboelfetoh et al., 2017; Lewis, et al, 2016). It aimed to assess nurses' knowledge related to patients' safety. It comprised two parts:

Part 1: Concerning socio-demographic characteristics for nurses related to their age, gender, marital status, educational level, position, years of work experience in the ICU, and attendance of training programs about patients' safety.

Part 2: Concerned with nurses' knowledge assessment. It consists of 6 parts as follow 
1- Nurses' knowledge about patients' safety: it consists of $2 \mathrm{MCQ}$.

2- Medication errors: it consists of $23 \mathrm{MCQ}$

3- Infection prevention: it consists of 14 MCQ

4- Pressure ulcer prevention: it consists of 7 MCQ and 23 Yes or No questions about nursing care of pressure ulcer.

5- Fall prevention: it consists of $20 \mathrm{MCQ}$.

6- Pain management: it consists of $11 \mathrm{MCQ}$.

7- Nurses' knowledge about care of intubated patient: it consists of $19 \mathrm{MCQ}$.

\section{Scoring system}

The correct answers were given one score and the wrong answers were given zero score. These scores were summed-up and converted into a percent score.

- Total knowledge score: 166 equal (100\%)

- Score from >80 referred to satisfactory knowledge.

- Score from 0-80 referred to unsatisfactory knowledge.

II: Patient safety practices observational checklist:

It was adapted from (Burns et al, 2020; Elgazar, et al, 2020; McCutcheon \& Doyle, 2018; Floyd, 2018; Aboelfetoh et al., 2017) and modified to suit the nature of the study after review of related literature. It was used to assess the nurses' practices related to safety measures in the ICU unit such as medication administration, infection control, safety measures for pressure ulcer prevention, safety measures for falls prevention, management of pain, safety measures for intubated patient and safety measures during transfer.

\section{Scoring system}

The response to each item in the procedures was categorized into the completely done, incompletely done and not done. Total score for every checklist was calculated and converted into percent, then categorized as follow: Scores of (1) were allotted to steps done correct (completely done), and zero were allotted to steps done incorrect (incompletely done and not done). Total nurses practice score was calculated then converted to mean percent score.

\section{Practice total score: 210 equal (100\%)}

- Score from >80referred to competent practice.

- Score from 0-80 referred to incompetent practice.

\section{III: Patients ' safety outcomes checklist}

This assessment sheet was developed by the researcher in English language after reviewing the related literature (Burns et al, 2020; Elgazar, et al, 2020; McCutcheon \& Doyle, 2018; Floyd, 2018). It comprised four parts:

Part1: Patients' socio-demographic characteristics will include: age, sex, medical history, diagnosis and duration of admission.

Part 2: This part concerned with assessed signs and symptoms of hospital acquired infection. It consists of three parts:

1- Laboratory investigation

2- General Signs and symptoms of infection

3- Local signs and symptoms of infection

Part 3: This part concerned with Physiological parameters for patient such as pulse, respiration, temperature, blood pressure and $\mathrm{O} 2$ saturation.

Part 4: This part concerned with clinical risk assessment tool are specific assessments that are used to measure levels of risk for certain procedures and out comes such as

- Braden scale which adopted from Braden et al., (1987) used to predict pressure sore risk. It is a summated rating scale composed of six subscales: sensory perception, moisture, activity, mobility, nutrition, friction and shear. The six subscales are related from 1 (least impairment) to 4 (most impairment) except friction and shear, which rates from 1-3. 
- Fall's risk assessment which adapted from Morse, Black \& Oberle (1989). Which used to predict the likelihood of a fall occurring and composed of six items: history of falling, secondary diagnosis, ambulatory aid, iv/heparin lock, gait/transferring and mental status.

- Critical pain assessment scale or the Critical-Care Pain Observation Tool (CPOT) which adopted from Gelinas, Fillion \&Puntillo (2009) to assess unconsciousness and critically ill adult patients' behaviors indicators for pain. It composed of four items: facial expression, body movement, muscle tension and compliance wit ventilator for intubated patients or vocalization for extubated patient. Each item of CPOT scored from (0 to 2) with total score of 8 it was divided.

\section{Nursing care protocol}

This protocol was developed by the researcher in the form of Arabic booklet after reviewing related literature (Elgazar, et al, 2020; Burns et al, 2020; Fleming \& Martin 2018; Aboelfetoh et al., 2017; Lewis, et al, 2016) and included theoretical and practical parts that conclude knowledge about i.e., a definition of patients' safety, a definition of adverse events, causes of adverse events and nurses' performance regarding safety measures about prevention of medication errors, prevention of infection, prevention of pressure ulcer, prevention of falls, management of pain, care of intubated patients and care during transfer.

\section{Validity and reliability of tools:}

The validity of the tools was ascertained by a group of five experts from medical surgical nursing department, faculty of Nursing, Benha University (one Professor, 2 assistant professors and 2 lecturer). Their opinions elicited regarding the format, consistency, accuracy, and relevancy of the tools; necessary modification was done accordingly

Reliability was testing statistically to assure that the tools are reliable before data collection. Testing reliability of the developed tools was done through Alpha Cronbach test .

-Alpha Cronbach reliability analysis for structured interviewing questionnaire was 0.77

- For observational checklist regards patient's safety was 0.81

-Alpha Cronbach reliability analysis for Clinical risk assessment tool was 0.85

- For Critical pain assessment scale was 0.83

\section{Pilot study:}

After the tools have been designed, they were tested through a pilot study and excluded from the result, which was done before embarking on the field work to check the clarity and feasibility of designed tools and to estimate the time needed to complete its items. It was carried out on $10 \%$ of nurses (6) who are working at Intensive Care Unit to estimate the proper time required for answering the questionnaire and $10 \%$ of patients (6) who admitted to ICU, according to the result of the pilot study. Some modification was performed as needed.

\section{Ethical considerations}

- The research approval was obtained from the ethical committee of faculty of nursing before initiating the study work.

- The researcher clarified the purpose and aim of the study to nurses and patients included in the study before data collection.

- Oral consent was obtained from nurses to participate in the study.

- The researcher assured maintaining, anonymity and confidentiality of subjects' data and that, it will be used for research purpose only.

- The subjects were informed that they are allowed to choose to participate in the study 
and they have the right to withdraw from the study at any time.

\section{Field of work:}

The process of data collection and teaching sessions extended over 12 months and starting at August 2020 till the end of July 2021, it was carried out by the researcher through four phases: -

\section{Assessment phase :}

The researcher visited ICU department (three days weekly morning and afternoon) to collect data.

\section{For nurses :}

- The nurse's structured questionnaire was used to assess their knowledge regarding critical patients' safety to identify the nurses' educational needs. These tools were filled by the nurses; it had taken about 4560 minutes to be filled.

- Nurses were observed by the researcher using observational checklists to assess their practice regarding safety measures in the ICU unit such as medication administration, infection control, safety measures for pressure ulcer prevention, safety measures for falls prevention, management of pain, safety measures for intubated patient and safety measures during transfer. It had taken for 45 minutes for each nurse; this phase of nurse's assessment took one month.

\section{For patients :}

- Patients (control group) were observed by the researcher using patient assessment sheet to assess patients' safety outcomes. It had taken 45 minutes for every patient; this phase took 3 months.

Planning Phase (nursing care protocol development):

Proposed protocol general and specific objectives were designed based on predetermined subjects' need, relevant recent literature, and opinions of the nursing experts. This protocol was revised and modified based on the experts' comments, in order to be implemented using various methods including a booklet contained major headlines of the nursing care protocol for critical patients' safety, which was designed by researcher, and written in a very simple Arabic language, as well as supplemented by photos.

\section{Implementation phase :}

- The implementation phase achieved through training sessions at period of 16 weeks. Nurses divided into groups each group contain 3 nurses, this phase took a period of 5 months in addition to one-month pre protocol baseline assessment and onemonth post protocol evaluation taking into consideration the use of Arabic language that suits the levels of nurses. Motivation and reinforcement during training session used in order to enhance motivation for sharing in the study. The total number of sessions for each group of nurses was 7 sessions for knowledge \& 6 sessions for practice with 45-60 minutes for every session including 10 minutes for discussion $\&$ feedback .

- Each session was started by a summary about what has been discussed in the previous session and the objectives of the new session, also, the session ended by a summary of its contents and feedback from the nurses was obtained to ensure that he/ she got the maximum benefit.

- Teaching methods for knowledge were lecture and group discussion. Meanwhile, demonstration and redemonstration. were for practice.

- The media utilized were handouts, posters, videos \& pictures.

- The content of training sessions covered in a booklet; each nurse obtained a copy of the Arabic booklet.

- At last sessions, the researcher informed them that they will be evaluated by the researcher immediately . 


\section{Evaluation phase:}

For nurses - :

Evaluation of the effect of the nursing care protocol on nurses' knowledge, practice was done by comparing the results pre and post immediately implementation of the protocol by using the same data collection tools (utilizing tool 1,2 ). This phase took one month .

For patients - :

The researcher assessed patients (study group) using patients safety outcome checklist (utilizing tool 3). The evaluation performed on admission and after one week, this phase took 3 months.

\section{Statistical analysis}

Data were verified prior to entry into the computer. The Statistical Package for Social Sciences (SPSS version 20) was used for that purpose, followed by data analysis and tabulation. Descriptive statistics were applied (e.g., mean, standard deviation, frequency and percentages). The statistical tests were used as Paired (t) test was used to compare mean scores between the same sample at different study phases while Chi square was used for number and percent distribution, and Spearman correlation test (r) was used to define correlation among socio- demographic characteristics and the study sample at different study phases. A highly significant level value was considered when $p \leq 0.001$, while a significant level value was considered when $\mathrm{p} \leq 0.05$, and insignificant when $\mathrm{p}>$ 0.05 .

\section{Results}

Table (1): Reveals that, $50.8 \%$ of the studied nurses were in the age category 25$<35$ years with the mean \pm SD33.1 \pm 2.31 , $71.4 \%$ were females and $82.5 \%$ were married. In relation to qualification, $57.2 \%$ had technical nursing institute and $69.8 \%$ were nurses. Regarding to years of experience, $55.6 \%$ had experience years from
$5-<10$ years and $81.0 \%$ hadn't attended any training courses related to patient safety in ICU.

Table (2): Shows that the mean score of total knowledge was $52.9 \pm 15.20$ pre nursing care protocol implementation, which improved to $132.5 \pm 37.9$ post nursing care protocol implementation. With highly statistically significant differences among all items pre and post nursing care protocol implementation at $(\mathrm{p} \leq 0.001)$.

Table (3): Demonstrates that, the total mean score of nurse's practices was $86.7 \pm 23.5$ pre nursing care protocol implementation. However, post implementation improved to $176.8 \pm 40.1$. also, there were highly statistically significant difference between all items pre $\&$ post implementation at $\mathrm{p}<0.001$.

Table (4): Shows that there is a highly significant positive correlation between total nurses' knowledge and their practice at pre and post implementation of nursing care protocol where $\mathrm{p}<0.001$.

Table (5): Reveals that regarding age (43.3\%, 40\% respectively) of both control $\&$ study group their age was from 51->60 years old with mean \pm SD was $(54.3 \pm 10.8$ \& $53.7 \pm 9.81$ respectively), regarding gender $(60 \%, 53.3 \%$ respectively) were males regarding medical history $(40 \%$, $33.3 \%$ respectively) of control \& study group had hypertension and $(26.7 \%$ \& $23.3 \%$ respectively) of control \& study group had history of previous ICU admission. Concerning diagnosis $(26.7 \%$ \& $30 \%$ respectively) of control \& study group had brain hemorrhage and duration of hospital stay was one day with percentage $(60 \%$ \& $56.7 \%$ respectively) of both groups.

Table (6): Clarifies that (40\%, $40 \%$ respectively) of both control and study group were at moderate risk on admission 
with no significant difference between them. While after one week $(26.7 \%, 50 \%$ respectively) of control and study group were at mild risk with highly statistically significant difference between both groups at $\mathrm{p} \leq 0.001$.

Table (7): Clarifies that $(46.7 \%, 40.7 \%$ respectively) of both control and study group were at moderate risk on admission with no significant difference between them. While after one week $(26.7 \%, 40 \%$ respectively) of control and study group were at low risk with highly statistically significant difference between both groups at $\mathrm{p} \leq 0.001$.
Table (8): Clarifies that (53.3\%, 50\% respectively) of both control and study group had moderate pain on admission with no significant difference between them. While after one week $(20 \%, 33.3 \%$ respectively) of control and study group had mild pain with highly statistically significant difference between both groups at $\mathrm{p} \leq 0.001$. 
Table (1): Number and percentage distribution of the studied nurses according to their sociodemographic characteristics $(\mathrm{N}=63)$

\begin{tabular}{|c|c|c|}
\hline \multirow[t]{2}{*}{ Socio demographic characteristics } & \multicolumn{2}{|c|}{$\begin{array}{c}\text { The studied } \\
\text { sample }(n=63)\end{array}$} \\
\hline & $\mathbf{N}$ & $\%$ \\
\hline \multicolumn{3}{|l|}{ Age (Year) } \\
\hline$<25$ & 10 & 15.9 \\
\hline $25-<35$ & $\overline{32}$ & 50.8 \\
\hline $35-<45$ & 15 & 23.8 \\
\hline $45-55$ & 6 & 9.5 \\
\hline \multicolumn{3}{|c|}{$33.1 \pm 2.31$} \\
\hline \multicolumn{3}{|l|}{ Gender } \\
\hline Male & 18 & 28.6 \\
\hline Female & 45 & 71.4 \\
\hline \multicolumn{3}{|l|}{ Marital Status } \\
\hline Single & 7 & 11.1 \\
\hline Married & 52 & 82.5 \\
\hline Divorced & 2 & 3.2 \\
\hline Widowed & 2 & 3.2 \\
\hline \multicolumn{3}{|l|}{ Position } \\
\hline Staff Nurse. & 53 & 84.1 \\
\hline Head Nurse & 10 & 15.9 \\
\hline \multicolumn{3}{|l|}{ Qualification } \\
\hline A high school diploma in nursing & 8 & 12.7 \\
\hline A technical nursing institute & 36 & 57.2 \\
\hline A bachelor's degree in nursing & 14 & 22.2 \\
\hline Postgraduate studies & 5 & 7.9 \\
\hline \multicolumn{3}{|l|}{ Job Title } \\
\hline A nursing specialist & 9 & 14.3 \\
\hline Assistance nurse & 44 & 69.8 \\
\hline Head nurse & 10 & 15.9 \\
\hline \multicolumn{3}{|l|}{ Experience years } \\
\hline$<5$ & 12 & 19 \\
\hline $5-<10$ & 35 & 55.6 \\
\hline $10-<15$ & 8 & 12.7 \\
\hline $15-<20$ & 5 & 7.9 \\
\hline$\geq 20$ & 3 & 4.8 \\
\hline Mean SD & & \\
\hline \multicolumn{3}{|c|}{$\begin{array}{l}\text { Attended any training course related to the safety measures of } \\
\text { critically ill patients }\end{array}$} \\
\hline Yes & 12 & 19 \\
\hline No & 51 & 81 \\
\hline \multicolumn{3}{|c|}{ If yes, When did you receive this training course $(n=12)$} \\
\hline Less than one year & 2 & 16.7 \\
\hline One year & 3 & 25 \\
\hline Three years & 7 & 58.3 \\
\hline
\end{tabular}


Table (2): Comparison between total nurses' knowledge pre and post implementation of nursing care protocol $(\mathrm{N}=63)$

\begin{tabular}{|c|c|c|c|c|c|c|c|c|c|c|}
\hline \multirow[t]{4}{*}{ Safety knowledge } & \multicolumn{8}{|c|}{ The studied sample $(n=63)$} & \multirow{2}{*}{\multicolumn{2}{|c|}{ 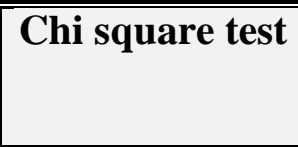 }} \\
\hline & \multicolumn{4}{|c|}{$\begin{array}{l}\text { Pre nursing care } \\
\text { protocol }\end{array}$} & \multicolumn{4}{|c|}{$\begin{array}{l}\text { Post nursing care } \\
\text { protocol }\end{array}$} & & \\
\hline & \multicolumn{2}{|c|}{$\begin{array}{l}\text { Satisfacto } \\
\text { ry }\end{array}$} & \multicolumn{2}{|c|}{$\begin{array}{l}\text { Unsatisfa } \\
\text { ctory }\end{array}$} & \multicolumn{2}{|c|}{$\begin{array}{l}\text { Satisfacto } \\
\text { ry }\end{array}$} & \multicolumn{2}{|c|}{$\begin{array}{l}\text { Unsatisfact } \\
\text { ory }\end{array}$} & \multirow[t]{2}{*}{$\mathbf{X}^{2}$} & \multirow[t]{2}{*}{ p-value } \\
\hline & $\mathbf{N}$ & $\%$ & $\mathbf{N}$ & $\%$ & $\mathbf{N}$ & $\%$ & $\mathbf{N}$ & $\%$ & & \\
\hline $\begin{array}{l}\text { Prevention of medication } \\
\text { errors }\end{array}$ & 26 & 41.3 & 37 & 58.7 & 54 & 85.7 & 9 & 14.3 & 41.55 & $.000^{* *}$ \\
\hline Prevention of infection & 24 & 38.1 & 39 & 61.9 & 52 & 82.5 & 11 & 17.5 & 36.87 & $.000 * *$ \\
\hline Prevention of bed sores & 18 & 28.6 & 45 & 71.4 & 50 & 79.4 & 13 & 20.6 & 40.58 & $.000 * *$ \\
\hline Prevention of fall & 25 & 39.7 & 38 & 60.3 & 54 & 85.7 & 9 & 14.3 & 37.68 & $.000^{* *}$ \\
\hline Pain assessment & 13 & 20.6 & 50 & 79.4 & 56 & 88.9 & 7 & 11.1 & 37.78 & $.000^{* *}$ \\
\hline Care of intubated patient & 16 & 25.4 & 47 & 74.6 & 55 & 87.3 & 8 & 12.7 & 32.91 & $.000^{* *}$ \\
\hline Total & 14 & 22.2 & 49 & 77.8 & 53 & 84.1 & 10 & 15.9 & 42.63 & $.000^{* *}$ \\
\hline Mean SD & \multicolumn{4}{|c|}{$52.9 \pm 15.20$} & \multicolumn{4}{|c|}{$132.5 \pm 37.9$} & & \\
\hline
\end{tabular}

(*) Statistically significant at $\mathrm{p} \leq 0.05$. (**) highly statistically significant at $\mathrm{p} \leq 0.001$.

Table (3): Comparison between total nurses' practice pre and post implementation of nursing care protocol $(\mathrm{N}=63)$

\begin{tabular}{|c|c|c|c|c|c|c|c|c|c|c|}
\hline \multirow{4}{*}{$\begin{array}{ll}\text { Safety } & \text { practice } \\
\text { regarding } & \end{array}$} & \multicolumn{8}{|c|}{ The studied sample $(\mathrm{n}=63)$} & \multirow{2}{*}{\multicolumn{2}{|c|}{$\begin{array}{l}\text { Chi } \\
\text { test }\end{array}$}} \\
\hline & \multicolumn{4}{|c|}{ Pre nursing care protocol } & \multicolumn{4}{|c|}{$\begin{array}{l}\text { Post nursing care } \\
\text { protocol }\end{array}$} & & \\
\hline & \multicolumn{2}{|c|}{ Competent } & \multicolumn{2}{|c|}{ Incompetent } & \multicolumn{2}{|c|}{ Competent } & \multicolumn{2}{|c|}{$\begin{array}{l}\text { Incompete } \\
\text { nt }\end{array}$} & \multirow[t]{2}{*}{$\mathbf{X}^{2}$} & \multirow[t]{2}{*}{$\begin{array}{l}\text { p- } \\
\text { value }\end{array}$} \\
\hline & $\mathbf{N}$ & $\%$ & $\mathbf{N}$ & $\%$ & $\mathbf{N}$ & $\%$ & $\mathbf{N}$ & $\%$ & & \\
\hline Medication administration & 30 & 47.6 & 33 & 52.4 & 52 & 82.5 & 11 & 17.5 & 34.32 & $.001^{* *}$ \\
\hline Medication error reporting & 10 & 15.9 & 53 & 84.1 & 48 & 76.2 & 15 & 23.8 & 32.36 & $.000 * *$ \\
\hline Infection control & 24 & 38.1 & 39 & 61.9 & 52 & 82.5 & 11 & 17.5 & 31.95 & $.000 * *$ \\
\hline Pressure ulcer prevention & 14 & 22.2 & 49 & 77.8 & 50 & 79.4 & 13 & 20.6 & 34.78 & $.000^{* *}$ \\
\hline Fall prevention & 25 & 39.7 & 38 & 60.3 & 50 & 79.4 & 13 & 20.6 & 25.30 & $.000 * *$ \\
\hline Pain management & 12 & 19.5 & 51 & 80.5 & 54 & 85.7 & 9 & 14.3 & 29.84 & $.000 * *$ \\
\hline Care of intubated patient & 20 & 31.7 & 43 & 68.3 & 55 & 87.3 & 8 & 12.7 & 25.51 & $.000^{* *}$ \\
\hline Total & 16 & 25.4 & 47 & 74.6 & 50 & 79.4 & 13 & 20.6 & \multirow[t]{2}{*}{33.08} & \multirow[t]{2}{*}{$.000^{* *}$} \\
\hline Mean SD & \multicolumn{4}{|c|}{$86.7 \pm 23.5$} & \multicolumn{4}{|c|}{$176.8 \pm 40.1$} & & \\
\hline
\end{tabular}

$(* *)$ highly statistically significant at $\mathrm{p}<0.001$.

Table (4): Correlation between total nurses' knowledge and their practice pre and post implementation of nursing care protocol $(\mathrm{N}=63)$.

\begin{tabular}{|c|c|c|c|}
\hline \multirow{2}{*}{\multicolumn{2}{|c|}{ Variables }} & \multicolumn{2}{|c|}{ Total nurses' practice } \\
\hline & & Pre & Post \\
\hline Total nurses' knowledge & $\begin{array}{l}\mathbf{r} \\
\mathbf{p}\end{array}$ & $\begin{array}{l}\mathbf{0 . 5 6 3} \\
.000 * * \\
\end{array}$ & $\begin{array}{l}0.541 \\
.000 * * \\
\end{array}$ \\
\hline
\end{tabular}

**highly significant at $\mathbf{p}<\mathbf{0 . 0 0 1}$ 
Table (5): Number and percentage distribution of the studied patients (control and study group) according to their socio-demographic data.

\begin{tabular}{|c|c|c|c|c|c|c|}
\hline \multirow[t]{2}{*}{$\mid \begin{array}{l}\text { Socio-Demographic Data } \\
\end{array}$} & \multicolumn{2}{|c|}{$\begin{array}{l}\begin{array}{l}\text { Control group } \\
(\mathbf{n}=30)\end{array} \\
\end{array}$} & \multicolumn{2}{|c|}{$\begin{array}{l}\text { Study group } \\
(n=30)\end{array}$} & \multicolumn{2}{|c|}{ Test of Sig. } \\
\hline & $\mathbf{N}$ & $\%$ & $\mathbf{N}$ & $\%$ & $\mathbf{X}^{2}$ & P-value \\
\hline \multicolumn{5}{|l|}{ Age (year) } & \multirow[t]{5}{*}{1.510} & \multirow[t]{5}{*}{.241} \\
\hline $30-40$ & 3 & 10 & 2 & 6.7 & & \\
\hline $41-50$ & 6 & 20 & 7 & 23.3 & & \\
\hline $51-60$ & 13 & 43.3 & 12 & 40 & & \\
\hline$>60$ & 8 & 26.7 & 9 & 30 & & \\
\hline Mean SD & \multicolumn{2}{|c|}{$54.3 \pm 10.8$} & \multicolumn{2}{|c|}{$53.7 \pm 9.81$} & $t=1.964$ & .209 \\
\hline \multicolumn{5}{|l|}{ Gender } & \multirow[t]{3}{*}{1.467} & \multirow[t]{3}{*}{.299} \\
\hline Male & 18 & 60 & 16 & 53.3 & & \\
\hline Female & 12 & 40 & 14 & 46.7 & & \\
\hline \multicolumn{5}{|l|}{ Medical history } & \multirow[t]{5}{*}{1.210} & \multirow[t]{5}{*}{.310} \\
\hline Hypertension & 12 & 40 & 10 & 33.3 & & \\
\hline Diabetes mellitus & 6 & 20 & 8 & 26.7 & & \\
\hline Cardiac disease & 4 & 13.3 & 5 & 16.7 & & \\
\hline Previous ICU admission & 8 & 26.7 & 7 & 23.3 & & \\
\hline \multicolumn{5}{|l|}{ Diagnosis } & \multirow[t]{7}{*}{.992} & \multirow[t]{7}{*}{1.017} \\
\hline Brain tumor & 4 & 13.3 & 4 & 13.3 & & \\
\hline Poly-trauma & 5 & 16.7 & 6 & 20 & & \\
\hline Heart failure & 3 & 10 & 3 & 10 & & \\
\hline Brain Hemorrhage & 8 & 26.7 & 9 & 30 & & \\
\hline Diabetic ketoacidosis & 3 & 10 & 3 & 10 & & \\
\hline Other & 7 & 23.3 & 5 & 16.7 & & \\
\hline \multicolumn{5}{|c|}{ Duration of hospital stay (Day) } & \multirow[t]{4}{*}{1.037} & \multirow[t]{4}{*}{.384} \\
\hline New admission & 5 & 16.7 & 7 & 23.3 & & \\
\hline One day & 18 & 60 & 17 & 56.7 & & \\
\hline Two days & 7 & 23.3 & 6 & 20 & & \\
\hline
\end{tabular}

No significant at $\mathbf{p}>\mathbf{0 . 0 5}$.

Table (6): Comparison between the studied patients (control and study group) regarding to total Braden scale on admission and after one week.

\begin{tabular}{|c|c|c|c|c|c|c|c|c|c|c|}
\hline \multirow[t]{3}{*}{ Total Braden scale } & \multicolumn{4}{|c|}{$\begin{array}{l}\text { Control group } \\
(\mathrm{n}=30)\end{array}$} & \multicolumn{4}{|c|}{$\begin{array}{l}\text { Study group } \\
(n=30)\end{array}$} & \multirow{3}{*}{$\begin{array}{l}\text { Test of } \\
\text { Sig. } \\
\left(p_{1}\right)\end{array}$} & \multirow{3}{*}{$\begin{array}{l}\text { Test of } \\
\text { Sig. } \\
\left(\mathbf{p}_{2}\right)\end{array}$} \\
\hline & \multicolumn{2}{|c|}{$\begin{array}{l}\text { On } \\
\text { admissio } \\
\text { n }\end{array}$} & \multicolumn{2}{|c|}{$\begin{array}{l}\text { After one } \\
\text { week }\end{array}$} & \multicolumn{2}{|c|}{$\begin{array}{l}\text { On } \\
\text { admission }\end{array}$} & \multicolumn{2}{|c|}{$\begin{array}{l}\text { After one } \\
\text { week }\end{array}$} & & \\
\hline & $\mathbf{N}$ & $\%$ & $\mathbf{N}$ & $\%$ & $\mathbf{N}$ & $\%$ & $\mathbf{N}$ & $\%$ & & \\
\hline No risk & 4 & 13.3 & 5 & 16.7 & 2 & 6.7 & 7 & 23.3 & \multirow{4}{*}{$\begin{array}{l}\mathrm{X}^{2}=1.3 \\
47 \\
\mathrm{P}=.322\end{array}$} & \multirow{4}{*}{$\begin{array}{l}X^{2}=12.12 \\
P=.000 * *\end{array}$} \\
\hline Mild risk & 6 & 20 & 8 & 26.7 & 7 & 23.3 & 15 & 50 & & \\
\hline Moderate risk & 12 & 40 & 11 & 36.7 & 12 & 40 & 6 & 20 & & \\
\hline Severe risk & 8 & 26.7 & 6 & 20 & 9 & 30 & 2 & 6.7 & & \\
\hline
\end{tabular}

$\mathrm{X}^{2}$ : Chi-square

$\mathrm{p}=\mathrm{p}$-value

$\mathrm{P}_{1}$ : $\mathrm{p}$ value for comparing between the (Control group and Study group) on admission.

$\mathrm{P}_{2}$ : $\mathrm{p}$ value for comparing between the (Control group and Study group) after one week.

**: Highly statistically significant at $p \leq 0.001$. No significant at $p>0.05$. 
Table (7): Comparison between the studied patients (control and study group) regarding to total fall's risk assessment on admission and after one week.

\begin{tabular}{|c|c|c|c|c|c|c|c|c|c|c|}
\hline \multirow{3}{*}{$\begin{array}{l}\text { Total fall's } \\
\text { risk } \\
\text { assessment }\end{array}$} & \multicolumn{4}{|c|}{$\begin{array}{l}\text { Control group } \\
(n=30)\end{array}$} & \multicolumn{4}{|c|}{$\begin{array}{l}\text { Study group } \\
(n=30)\end{array}$} & \multirow{3}{*}{$\begin{array}{l}\text { Test of } \\
\text { Sig. } \\
\left(p_{1}\right)\end{array}$} & \multirow{3}{*}{$\begin{array}{l}\text { Test of } \\
\text { Sig. } \\
\left(p_{r}\right)\end{array}$} \\
\hline & \multicolumn{2}{|c|}{$\begin{array}{l}\text { On } \\
\text { admission }\end{array}$} & \multicolumn{2}{|c|}{$\begin{array}{l}\text { After one } \\
\text { week }\end{array}$} & \multicolumn{2}{|c|}{$\begin{array}{l}\text { On } \\
\text { admission }\end{array}$} & \multicolumn{2}{|c|}{$\begin{array}{l}\text { After one } \\
\text { week }\end{array}$} & & \\
\hline & $\mathbf{N}$ & $\%$ & $\mathbf{N}$ & $\%$ & $\mathbf{N}$ & $\%$ & $\mathbf{N}$ & $\%$ & & \\
\hline Low risk & 6 & 20 & 8 & 26.7 & 5 & 16.7 & 12 & 40 & \multirow{3}{*}{$\begin{array}{l}X^{2}= \\
1.119 \\
P=. r \wedge V\end{array}$} & \multirow{3}{*}{$\begin{array}{l}X^{2}=1 \varepsilon . \cdot 1 \\
P=.000 * *\end{array}$} \\
\hline Moderate risk & 14 & 46.7 & 12 & 40 & 14 & 46.7 & 11 & 36.7 & & \\
\hline High risk & 10 & 33.3 & 10 & 33.3 & 11 & 36.7 & 7 & 23.3 & & \\
\hline
\end{tabular}

$\mathrm{X}^{2}$ : Chi-square

$\mathrm{p}=\mathrm{p}$-value

$\mathrm{P}_{1}$ : $\mathrm{p}$ value for comparing between the (Control group and Study group) on admission.

$\mathrm{P}_{2}$ : $\mathrm{p}$ value for comparing between the (Control group and Study group) after one week.

$* *$ : Highly statistically significant at $\mathrm{p} \leq 0.001$. No significant at $\mathrm{p}>0.05$.

Table (8): Comparison between the studied patients (control and study group) regarding to total critical pain assessment scale on admission and after one week.

\begin{tabular}{|c|c|c|c|c|c|c|c|c|c|c|}
\hline \multirow{3}{*}{$\begin{array}{l}\text { Total critical } \\
\text { pain assessment } \\
\text { scale }\end{array}$} & \multicolumn{4}{|c|}{$\begin{array}{l}\text { Control group } \\
(n=30)\end{array}$} & \multicolumn{4}{|c|}{$\begin{array}{l}\text { Study group } \\
(n=30)\end{array}$} & \multirow{3}{*}{$\begin{array}{l}\text { Test of } \\
\text { Sig. } \\
\left(\mathbf{p}_{1}\right)\end{array}$} & \multirow{3}{*}{$\begin{array}{l}\text { Test of } \\
\text { Sig. } \\
\left(\mathbf{p}_{2}\right)\end{array}$} \\
\hline & \multicolumn{2}{|c|}{$\begin{array}{l}\text { On } \\
\text { admission }\end{array}$} & \multicolumn{2}{|c|}{$\begin{array}{l}\text { After one } \\
\text { week }\end{array}$} & \multicolumn{2}{|c|}{$\begin{array}{l}\text { On } \\
\text { admission }\end{array}$} & \multicolumn{2}{|c|}{$\begin{array}{l}\text { After one } \\
\text { week }\end{array}$} & & \\
\hline & $\mathbf{N}$ & $\%$ & $\mathbf{N}$ & $\%$ & $\mathbf{N}$ & $\%$ & $\mathbf{N}$ & $\%$ & & \\
\hline \begin{tabular}{|l} 
No pain \\
\end{tabular} & 2 & 6.7 & 2 & 6.7 & 2 & 6.7 & 4 & 13.3 & \multirow{4}{*}{$\begin{array}{l}X^{2}= \\
0.874 \\
p=.900\end{array}$} & \multirow{4}{*}{$\begin{array}{l}X^{2}= \\
10.66 \\
P=.003 \\
* *\end{array}$} \\
\hline Mild pain & 4 & $\begin{array}{l}13.3 \\
\end{array}$ & 6 & 20 & 3 & 10 & 10 & 33.3 & & \\
\hline Moderate pain & 16 & 53.3 & 15 & 50 & 15 & 50 & 12 & 40 & & \\
\hline Severe pain & 8 & 26.7 & 7 & 23.3 & 10 & 33.3 & 4 & 13.3 & & \\
\hline
\end{tabular}

t: $t$. test

$\mathrm{p}=\mathrm{p}$-value

$\mathrm{P}_{1}$ : $\mathrm{p}$ value for comparing between the (Control group) on admission and after one week.

$\mathrm{P}_{2}$ : $\mathrm{p}$ value for comparing between the (Study group) on admission and after one week.

**: Highly statistically significant at $\mathrm{p} \leq 0.001$. No significant at $\mathrm{p}>0.05$.

\section{Discussion}

Regarding to the socio demographic characteristics of intern-nurses, the findings of the present study revealed that more than half of studied nurses were at the age group between $25-<35$ years old with mean \pm SD $33.1 \pm 2.31$. This may reflect the demanding nature of critical care units service, so that older nurses may find it difficult to cope with the load of work required and newly graduate preferred to work in the critical care units as they have the ability to acquire knowledge and change their behaviors based on submission of up to date knowledge. This result is in line with Mamdouh etal., (2020) who studied about "assessment of nurses' performance regarding the implementation of patient safety measures in intensive care units" stated that nearly three quarters of the respondents were age ranged between 20-30 years.

In the present study, more than two thirds of the studied nurses were females. This may be due to the greatest fraction of the nurses in Egypt was females and may related 
to the studying of nursing in Egyptian universities were exclusive for females only until few years ago. These findings are in consistent with Hassanin, (2016) who studied about "nurses' performance regarding the neurological assessment in neurological unit" reported that three quarters of the study subject were females. But it disagrees with Alrubaiee, et al., (2017) in their study about "Knowledge and practices of nurses regarding nosocomial infection control measures in private hospitals in Sana'a City, Yemen" stated that the highest percentage of nurses were males $(61.2 \%)$.

Regard to marital status, the result of the study reveals that, majority of the studied nurses were married. This finding is in agreement with, Mahmood and Khudur (2016) who reported that majority of the studied nurses were married. From the researcher point of view this may be due to the studied nurses were at the age group that known in Egypt that they married.

Concerning qualification, the current study finding shows that more than half of the study nurses had technical nursing institute, this is in the same line with Mamdouh, et al., (2020) who reported that nearly half of the study nurses had technical nursing institute. But this results disagrees with El-Gendi etal., (2017) in his study entitled" assessment of patient safety culture among Egyptian healthcare employees " showed that all ICU nurses had a bachelor's degree in nursing science.

Concerning years of experience, the current study finding showed that more than half of the studied nurses had 5-<10 years of experience, this explains that most of those nurses were newly graduated, young and tolerate the nature of the work. This result is in agreement with Said, (2015) his study entitled "Knowledge and practice of intensive care nurses on prevention of ventilator associated pneumonia at Muhimbili National Hospital" who found that more than two thirds of nurses were working in ICU for less than 10 years.

Regard to past training courses about patient safety, the result of current study revealed that majority of nurses had not attended any training courses related to patient safety in ICU. The finding of the current study can be explained in the light of the belief that lack of hospital financial resources for training or shortage of nursing staff and work overload which considered as a barrier for nurses to leave the work and attend training course. This finding is in agreement with Ragheb, \& Metwally (2016) who conducted a study entitled "Effect of training program on reduction of nurse's medication errors" and stated that few of staff nurses attended training program about medication administration.

Regarding total nurses' knowledge at pre and post implementation of nursing care protocol. The current study result revealed that the mean score of total knowledge was increased post nursing care protocol implementation than before. Also, there were highly statistically significance difference between all items of knowledge at $\mathrm{p} \leq 0.001$.

This result of study is in the same line with study done by Samad et al., (2019) entitled " Effect of training program on nurses' performance regarding care for patients under mechanical ventilator in intensive care units " stated that there were significant differences increase in total nurse knowledge score throughout the study.

As regard to total nurses' practice at pre and post implementation of nursing care protocol. The current study result revealed that, total mean score of all practices were improved post nursing care protocol implementation than pre implementation with 
highly statistically significant differences between all practices pre and post implementation.

This is supported by Abdelmoaty et al., (2020) who conduct their study to evaluate effect of training on nurses' knowledge and skills and revealed that there was a highly statistically significant difference between levels of acquired nurses' practices pre/post the interactive training. Moreover, this finding is in agreement with Mahmoud, et al., (2020) who concluded that there was a statistically significant difference between before and after an educational program for patient on mechanical ventilation regarding total nurses' practice scores. Adding, that adequate performance infection controls standard precautions, which increased after application of education.

This result of study is in the same line with study done by Samad et al., (2019) stated that there was highly statistical significance difference on the nurses practice at pre, post the training the program as patient safety considerations are worth noting first. Patients receiving mechanical ventilation in ICU require continuous observation and monitoring

Regarding sociodemographic characteristics of studied patients, the current study revealed that nearly two fifths of both control \& study group at age group from 51$>60$ years old with mean of age $54.3 \pm 10.8 \&$ $53.7 \pm 9.81$, respectively. From the researcher point of view this may be due to people in this age category, face many respiratory and cardiovascular diseases or infection which affect seriously on patient condition and require ICU admission.

This result is consistent with Aysha \& Ahmed., (2019) who studied about " The effect of implementing clinical alarm nursing intervention program on nurses' knowledge, practice and patient outcomes at intensive care unit " reported that no statistically significant difference was found between two groups in relation sociodemographic characteristics and medical characteristics It was observed that more than one third of control and study group had age between $40-<50$ years.

This finding is in agreement with Dawood, et al., (2016) who study about "effect of implementing a protocol of nursing care on hemodialysis patients ' safety outcomes", who reported that, the majority of the patients were at the age group $50<60$. According to Mohamed \& Ibraheem, (2019) who reported that more than half of the control and study group in the age category between $50-<60$.

Regarding gender the current study revealed more than half of the studied patients (study and control group) were male. This result is consistent with Rivera-Izquierdo, (2020) who study about "Sociodemographic, clinical and laboratory factors on admission associated with COVID-19 mortality in hospitalized patients " who reported that slightly more than half of our patients were males. According to Mohamed \& Ibraheem, (2019) who reported that more than half of studied patients in the control and study group were males.

Regarding medical history, the current study revealed that two fifths of control group and one third of study group had hypertension. This might be due to two fifths of control and study group were at age category 51>60 and in this age most people in Egypt suffer from chronic diseases as hypertension and diabetes mellitus also, this could be as a most common diseases reported all over the world in both developed and developing countries. 


\section{Effect of Implementing Nursing Care Protocol on Critical Patients' Safety Outcomes}

This finding is in agreement with Saad, et al., (2021) who studied about " Impact of Educational Program for Hepatic Encephalopathy on Nurse's Performance and Patient's Outcomes", the majority of studied patients had hypertension, and more than half had Diabetes Mellitus (DM) are associated diseases. According to Mohamed \& Ibraheem, (2019) who reported that more than one quarter of studied patients in the control and study group had hypertension.

Regarding diagnosis, also the current study revealed that more than one quarter of control \& study group diagnosed with brain hemorrhage. This might be due to they suffer from hypertension which is the leading cause of brain hemorrhage \& stroke. Also, the current study reveals that there were no statistically difference between control \& study group regarding sociodemographic data and medical history with $\mathrm{p}>0.05$ which indicated the two groups were nearly homogenous.

This finding is in the line with Mohamed \& Ibraheem, (2019) who reported that more than one quarter of control \& study group diagnosed with brain hemorrhage \& stroke.

In concerning to the comparison between the studied patients (control and study group) related to total Braden scale on admission and after one week. The current study clarified that two fifth of both control and study group were at moderate risk on admission with no significant difference between them was found. While after one week less than one third and nearly half of control and study group were at mild risk, respectively, with highly statistically significant difference between both groups at $\mathrm{p} \leq 0.001$. This finding is in the line with Mohamed \& Ibraheem, (2019) who reported that more than one-third of the control and study group were at severe risk on admission, while after two weeks, around one-third and one-fourth of the study group were at moderate risk and mild risk, respectively.

This finding is in agreement with Mohammed, et al., (2018) whose study indicated that, there was significant difference between the study and control groups on the 3rd day, and high significant difference at the 7th day related to risk assessment by Braden scale was found. Also, this finding is in agreement with Atyea, et al., (2013) whose study indicated that, on the day of admission, there was no significant difference between the study and control groups related to risk assessment was noted, but there was significant difference at 2 nd to 4 th day. There was moderate significant difference at 5 th to 6th day then there was highly significant difference at 7 th day.

This finding is in the line with Mohamed \& Weheida, (2015) who reported that $80 \%$ of all patients were at risk for pressure ulcers based on the total score of the Braden scale pre application of program, while the lowest prevalence among patients was represented a $30 \%$ after implementing of programs.

Regarding to total fall's risk assessment on admission and after one week. The study clarifies that less than half of both control and study group were at moderate risk on admission with no significant difference between them. While after one week, one fifth and two fifth, respectively of control and study group were at low risk with high statistically significant difference between both groups at $\mathrm{p} \leq 0.001$.

This finding is in agreement with Montejano-Lozoya et al., (2020) who study about " Impact of nurses' intervention in the prevention of falls in hospitalized patients" who concluded that, the systematic assessment of the risk of a patient falling during the hospital processes has proved to be 
an effective intervention to reduce the incidence of falls, especially in the elderly, who have the most falls. It is, therefore, necessary to implement specific advanced training for all nurses and not as a voluntary training program. There is a need to further improve the evidence on clinical practices to ensure patient safety (such as fall risk prevention), especially with experimental studies.

Regarding to total critical pain assessment scale on admission and after one week. The study clarifies that half of both control and study group had moderate pain on admission with no significant difference between them. While after one week one fifth and one third respectively of control and study group had mild pain with highly statistically significant difference between both groups at $\mathrm{p} \leq 0.001$.

This result agrees with Georgiou etal.,.(2019) in his study entitled "The effectiveness of systematic pain assessment on critically ill patient outcomes: A randomized controlled trial" stated that The incidence of pain according to total critical pain assessment scale in the intervention group was significantly lower compared to the control group $(p<.001)$. These findings are supporting the third research hypothesis

At the same line study done by Nasr et al., (2019) entitled as "Effect of Teaching Program on Critical Care Nurses' Performance About end-of-Life Care for Hepatic Patients" In their study showed that there was relation found between knowledge and practice score before and after the teaching program.

\section{Conclusion}

- The total mean score of nurses' knowledge was more improve after implementation of nursing care protocol than pre implementation. With highly statistically significant differences among all items pre and post nursing care protocol implementation was found ( $\mathrm{p} \leq 0.001)$.

- The total mean score of nurses' practice was more improve after implementation of nursing care protocol than pre implementation. Also, there were highly statistically significant difference between all items pre \& post implementation at $\mathrm{p}<0.001$.

- There was a high significant positive correlation between total nurses' knowledge and their practice at pre and post implementation of nursing care protocol where $\mathrm{p}<0.001$.

- There was an improvement in patient' safety outcomes for study group than control group after one week with statistically significance difference.

\section{Recommendation:}

- In service education should provide in hospital to improve nurses' performance regarding patient safety measures through acquiring knowledge and through implementing the established standards of care which must be updated periodically.

- Standard nursing procedures booklets should be available and developed in areas of patient safety in both Arabic and English language.

- Posters and simple illustrations about precaution of patient safety should be available in every intensive care unit.

- Close supervision and teaching on spot is needed to ensure that quality of care is provided by nurses while performing any procedures related to patient safety.

\section{Related to future research:}

- A similar study should be replicated on a large sample and other place to generalize the findings.

\section{References}

Abd Elhady, M. S. (2015). Impact of Teaching Guidelines on Improving Nurse's Performance and Patient's Safety Regarding Nosocomial Infection in Dialysis Unit. 
Doctoral dissertation, Benha University. Pp. 86-90.

Abdelmoaty, A., A Sabry, H., H ElSebaie, E., \& M Kenawy, A. (2020). Indwelling Urinary Catheter: Effect of Training on Nurses Knowledge and Skills. The Egyptian Family Medicine Journal, 4(1), 144-157.

Aboelfetoh, M., El Bitar, E.A., Eid, N., \& Mahmoud, S. (2017). Effects of an Educational Program on the Nurses' performance regarding Vascular Access Infection Prevention. Thesis for doctoral degree in nursing science, Medical Surgical Nursing, Faculty of Nursing, Benha University, Pp. 40-44.

Abu-El-Noor, N. I., Abu-El-Noor, M. K., Abuowda, Y. Z., Alfaqawi, M., \& Böttcher, B. (2019). Patient safety culture among nurses working in Palestinian governmental hospital: a pathway to a new policy. BMC health services research, 19(1), $1-11$.

AL-Ishaq, M. (2014). Nursing perceptions of patient safety at Hamad Medical Corporation in the State of Qatar. Doctoral dissertation, faculty of the University Graduate School in partial fulfillment of the requirements for the degree Doctor of Philosophy School of Nursing, Indiana University. Pp. 72-75.

Alrubaiee, G. G., Baharom, A., Faisal, I., Shahar, H. K., Daud, S. M., \& Basaleem, H. O. (2021). Implementation of an educational module on nosocomial infection control measures: a randomised hospitalbased trial. BMC nursing, 20(1), 1-10.

Ateyea, A., Mohamed, R., \& Abdel-Aziz, M. (2013). The effect of nursing guidelines for preventing pressure ulcers in intensive care units on patient outcomes. AAMJ, 10(3), 179-201.

Aysha, Z. M., \& Ahmed, S. E. (2019). The effect of implementing clinical alarm nursing intervention program on nurses' knowledge, practice and patient outcomes at intensive care unit. Am. J. Nurs. Res, 7, 824835 .

Bouldin, E., Andresen, E., Dunton, N., Simon, M., Waters, T. and Liu, M., et al. (2016). Falls among adult patients hospitalized in the United States: prevalence and trends. J Patient Saf; 9(1):13-7.

Burns, Z., Dykes, P. C., Adelman, J., Benneyan, J., Bogaisky, M., Carter, E., ... \& Bates, D. W. (2020). Evaluation of a patient-centered fall-prevention tool kit to reduce falls and injuries: a nonrandomized controlled trial. JAMA network open, 3(11), e2025889-e2025889.

Chinn, P. \& Kramer, M. (2017). Integrated Theory and Knowledge Development in Nursing, 8thedn. St Louis, MO: Mosby.

Dawood, R., El-Sebai, L., Salem, Y. M., \& Hussein, R. A. Y. A. (2016). Effect of implementing a protocol of nursing care on hemodialysis patients' safety outcomes. IOSR Journal of Nursing and Health Science, 5(5), 31-43.

Elgazar, W., Raghep, M.M., Mohamed, H., \& Mohamed, R. (2020). Effects of an Educational Program on the Nurses' performance regarding Vascular Access Infection Prevention. Thesis for doctoral degree in nursing science, Medical Surgical Nursing, Faculty of Nursing, Benha University, Pp. 76-80. 
El-Gendi, S., Seung, H., Abdelsamie, S.M., Feemster, A.A. (2017). Assessment of Patient Safety Culture among Egyptian Healthcare Employees. Med Saf Glob Health 6: 134. doi: 10.4172/25740407/100013

Fleming, E., Martin, D., (2018). Children \& Young People's Nursing Skills at a Glance, Wiley Blackwell, $1^{\text {st }}$ ed, UK,p39 .

Elmontsri, M., Banarsee, R., \& Majeed, A. (2018). Improving Patient Safety in Developing Countries - Moving Towards An Integrated Approach. JRSM open, 9(11), Pp. 61- 70.

Floyd, N. A. (2018). Effectiveness of Pressure Ulcer Protocols with the Braden Scale for Elderly Patients in the Intensive Care Unit: A Systematic Review (Doctoral dissertation, Walden University nd Doctoral Studies. 6018. https://scholarw orks. Wal denu.edu/dissertations/6018

Gaspar, S., Peralta, M., Marques, A., Budri, A., \& Gaspar de Matos, M. (2019). Effectiveness on hospital-acquired pressure ulcers prevention: a systematic review. International wound journal, 16(5), 1087-1102.

Georgiou, E ., Paikousis,L., Lambrinou,E, Merkouris,A.(2019).The effectiveness of systematic pain assessment on critically ill patient outcomes: A randomized controlled trial, Australian Critical Care, https://doi.org/10.1016/j.aucc.2019.09.004.

Gundlapalli, A., Jaulent, M., \& Zhao, D., (2018). precision health care through informatics $\left(1^{\text {st }}\right.$ ed.). International medical informatics association and ios press, Netherland, PP: 122-123.
Hanan Mohammed Mohammed, H. M. M., \& Abdallah, D. (2018). MEDICATION ERRORS IN CRITICAL CARE UNIT. Mansoura Nursing Journal, 5(1), 212-215.

Hanan Mohammed Mohammed, H. M. M., \& Abdallah, D. (2018). MEDICATION ERRORS IN CRITICAL CARE UNIT. Mansoura Nursing Journal, 5(1), 212-215.

Hassanin, H. (2016). Entitil for' nurses performance regarding the neurological assessment in neurological unit, Page. 50.

Joint Commission International (JCI) (2016). Joint Commission International purpose. Available at: http://www.jointcommission international.org/ (last accessed: 6/12/2016)

Lewis, S. L., Bucher, L., Heitkemper, M. M., Harding, M. M., Kwong, J., \& Roberts, D. (2016). Medical-Surgical Nursing-E-Book: Assessment and Management of Clinical Problems, Single Volume. Elsevier Health Sciences.

Mahmood, W., \& Khudur, K. (2016). Assessment of Nurses' Knowledge toward Vascular Access Devices for Patients with Hemodialysis at Baghdad, Journal of Nursing and Health Science 5(5): 69, doi: 10.9790/1959.

Mahmoud, E. A. E. N., EL-shafie, O. A. E. G., \& Abdel-Aziz, M. A. (2020). Effect of Educational Program for Nurses Performance Regarding Infection Control Precautions, toward patient on Mechanical Ventilation. Assiut Scientific Nursing Journal, 8(20), 94-104.

Mamdouh, E. A., Mohamed, H. S., \& Abdelatief, D. A. (2020). Assessment of 
Nurses' Performance Regarding the Implementation of Patient Safety Measures in Intensive Care Units. Egyptian Journal of Health Care, 11(1), 82-100. doi: 10.21608/ejhc.72596

McCutcheon J. A. \& Doyle G. R. (2018).Clinical Procedures for Safer Patient Care. recent edition, Victoria, British Columbia Institute of Technology, Pp. 589598. Available at https://opentextb c.ca/clinicalskills/: Accessed at 30.06.18.

Mohamed, S. A., \& Weheida, S. M. (2015). Effects of implementing educational program about pressure ulcer control on nurses' knowledge and safety of immobilized patients. Journal of nursing education and practice, 5(3), 12.

Mohamed, S. S., \& Ibraheem, R. A. (2019). Effect of Preventive Bundle Care on Nurses' Knowledge, Compliance and Patients' Outcome Regarding Pressure Ulcer in the Intensive Care Unit. Evidence-Based Nursing Research, 1(4), 12-12.

Mohammed, A., Othman, W., \& Shereif, W. (2018). Effect of Nursing Care Guidelines for Pressure Ulcers Prevention To Orthopedic Immobilized Patients. Mansoura Nursing Journal, 5(1), 55-65.

Mohammed, M. A., Abdel-Aziz, M. A., \& Soliman, M. S. S. (2020). Effect of implementing nursing care protocol about acute lung injury on patients' outcomes. Thesis for doctoral degree in Critical Care \& Emergency nursing, Faculty of Nursing, Assuit University. 74-76.

Montejano-Lozoya, R., Miguel-Montoya, I., Gea-Caballero, V., Mármol-López, M. I., Ruíz-Hontangas, A., \& Ortí-Lucas, R.
(2020). Impact of Nurses' Intervention in the Prevention of Falls in Hospitalized Patients. International Journal of Environmental Research and Public Health, 17(17), 6048.

Moursy, a., \& Sharaf, a., (2017). Vascular access care at hemodialysis unit; nurses' compliance to infection prevention and control practices Journal of Nursing and Health Science 6 (2):61-69.

Najafpour, Z., Godarzi, Z., Arab, M., \& Yaseri, M. (2019). Risk factors for falls in hospital in-patients: a prospective nested case control study. International journal of health policy and management, 8(5), 300.

Nasr, N.H., Ameen, N.F., Mohammed, M.A\& Abd El hafiz,A.I.,(2019). Effect of an Teaching Program on Critical Care Nurses's Performance About end of Life Care for Hepatic Patients, Assiut Scientific Nursing Journal, Vol , (6) No , (14).

Ragheb, S. E., \& Metwally, F. G. (2016). Effect of Training Program on Reduction of Nurse's Medication Errors. Zagazig Nursing Journal, 12(2), 116-133.

Rivera-Izquierdo, M., del Carmen ValeroUbierna, M., R-delAmo, J. L., FernandezGarcia, M. A., Martinez-Diz, S., TaheryMahmoud, A. and Jimenez-Mejias, E. (2020). Sociodemographic, clinical and laboratory factors on admission associated with COVID-19 mortality in hospitalized patients: A retrospective observational study. PLoS One, 15(6), e0235107.

Saad Mahmoud, H., Abd Elkader Mohammed, L., Said Taha, A., \& El Sayed Ghonaem, S. (2021). Impact of Educational Program for Hepatic Encephalopathy on Nurses Performance and 
Patients Outcomes. Journal of Nursing Science Benha University, 2(2), 190-202.

Said, A. (2015). Knowledge and practice of intensive care nurses on prevention of ventilator associated pneumonia at Muhimbili national hospital, MSc Nursing (Critical Care and Trauma) Dissertation. Muhimbili University of Health and Allied Sciences J., Daressalaam, Tanzania, 22(1): p.332.

Samad, Ola \& Ahmed, Dr \& Mohamed, Dr \& Elhamied, Dr. (2019). Effect of Training Program on Nurses' Performance Regarding Care for Patients under Mechanical Ventilator in Intensive Care Units. Thesis for doctoral degree in nursing science, Medical Surgical Nursing, Faculty of Nursing, Benha University, Pp. 80-82.

Sayed S, Younis G and Al-Metyazidy $\mathbf{H}$. (2017). Effect of Shallow versus Deep Endotracheal Tube Suctioning on Hemodynamic Parameters in mechanically ventilated patients in Intensive Care Unit. (IOSRJNHS2017; 6(4) 28-38.

Seliman, A. M., Morsy, W. Y., Sultan, M. A., Elshamy, K. F., \& Ahmed, H. H. E. (2014). Impact of a designed head trauma nursing management protocol on critical care nurses $^{\text {ee }}$ knowledge and practices at emergency hospital Mansoura University. Journal of American science, 10(12), 13-25.

Shehab, M., Ibrahim, N., \& Abd-Elkader, H. (2018). Impact of an educational program on nurses' knowledge and practice regarding care of traumatic brain injury patients at intensive care unit at Suez Canal University Hospital. International Journal of Caring Sciences, 11(2), 1104
World Health Organization (WHO), (2019). Patient safety- Global action on patient safety. Report by the DirectorGeneral. Geneva: (https://apps.who.int/gb/ebwha/pdf_files/W HA72/A72_26-en.pdf, accessed 23 July 2019).

Yilmaz, Z. \& Goris, S. (2015). Determination of the patient safety culture among nurses working at intensive care units. Pak J Med Sci; 31(3):597-601. 


\section{تأثير تطبيق بروتوكول الرعاية التمريضية على نتائج سلامة المرضى الحرجة اماني علي محمودـ مروة مصطفى راغبـ صباح سعيد حمح - راوية علي ابر اهيم}

تعتبر سلامة المرضى من المبادئ الأساسية في جميع أماكن الرعاية الصحية. ومع ذلك ، لا تزال

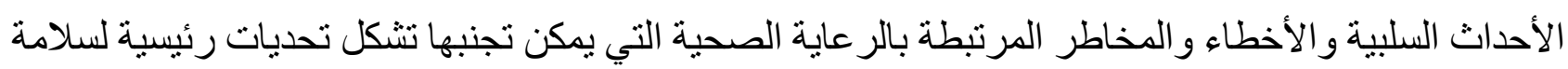

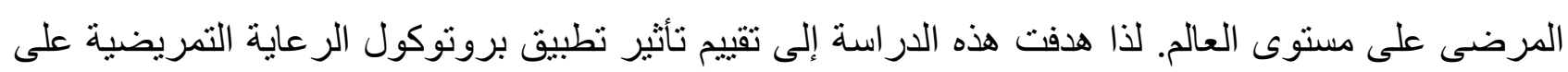
نتائج سلامة المرضى الحرجة. وقد أجريت هذه الدراسة في وحدة العناية المركزة العامة بمستشفى جامعة بنها.

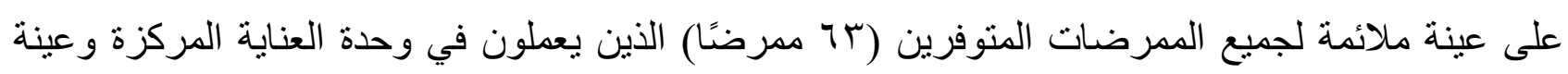

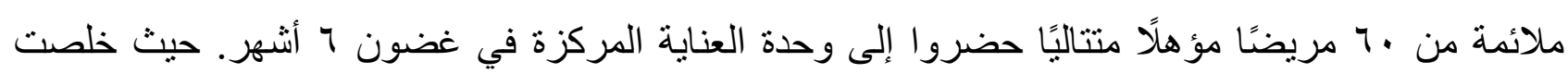

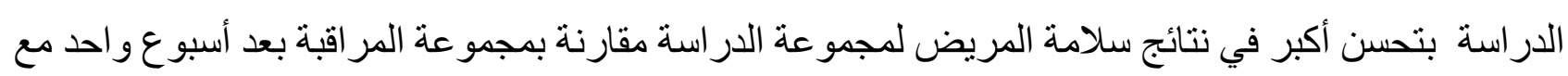

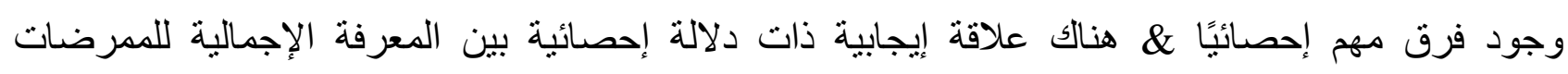

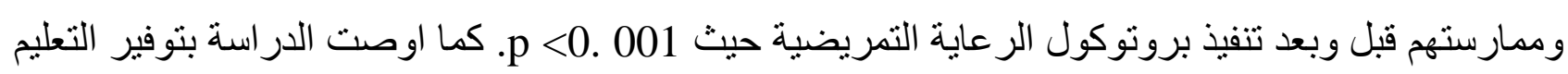

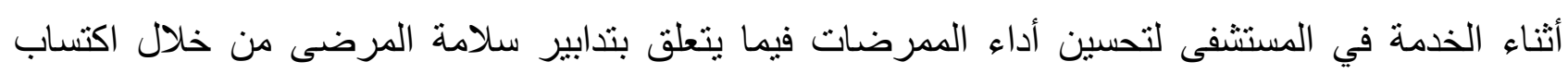
المعرفة وتنفيذ معايير الرعاية المعمول بها والتي يجب تحديثها بشكل دوري. 